\title{
Pericardial actinomycosis with cardiac tamponade from a contiguous thoracic lesion
}

\author{
A DAVID SLUTZKER, WILLIAM D CLAYPOOL \\ From the Department of Medicine, University of Illinois College of Medicine at Chicago, and the West Side \\ Veterans Administration Medical Center, Chicago, Illinois, USA
}

ABSTRACT A case of acute pericardial tamponade due to actinomycotic infection is reported, in which computed tomography showed a mass adjacent to the heart and a pericardial effusion. The patient had aggressive medical treatment with penicillin and survived.

About a quarter of actinomycotic infections produce thoracic disease, which is second in frequency only to cervicofacial actinomycosis.' Cardiac disease secondary to thoracic actinomycosis is unusual and pericardial tamponade due to this is rare. ${ }^{23}$

\section{Case report}

A 36 year old white man was found to have an abnormal chest radiograph while he was being investigated for disability resulting from a low back injury. He complained of pleuritic left anterior chest pain, exertional dyspnoea, and a non-productive cough. The patient underwent fibreoptic bronchoscopy and percutaneous fine needle aspiration of the lesion in another hospital and these investigations were reported to be non-diagnostic. He was treated with an unknown regimen of oral antibiotics for three weeks, after which he reported a modest subjective improvement. He was then lost to follow up.

Eleven months later, the patient complained of two months' deterioration with decreased appetite, a weight loss of $13.6 \mathrm{~kg}$, worsening exertional dyspnoea, progressive orthopnoea, and a dull constant left anterior chest pain. He had a cough that produced tenacious yellow sputum and had recently had an episode of streaky haemoptysis.

On presentation the patient was in mild respiratory distress. His oral temperature was $37.8^{\circ} \mathrm{C}$, his pulse 90 beats/min and regular, and his respiratory rate $20 / \mathrm{min}$; no pulsus paradoxus was observed. His oropharynx was remarkable for poor dentition, with extensive caries and periodontal disease. No cervical adenopathy or jugular venous distension was noted. He had soft expiratory wheez-

Address for reprint requests: Dr William D Claypool, Section of Respiratory and Critical Care Medicine, Department of Medicine, Clinical Sciences Building, University of Illinois College of Medicine at Chicago, PO Box 6998 Chicago, Illinois 60680, USA.

Accepted II January 1989 ing at both bases. Also noted was a firm, poorly circumscribed, tender left anterior chest wall mass $6 \mathrm{~cm}$ in diameter: Cardiac examination showed decreased intensity of both the $\vec{N}$ first and the second heart sound but no murmur or rub.

Abnormal laboratory results included microcytic anaemia (haemoglobin concentration $11.3 \mathrm{~g} / \mathrm{dl}$ ), a white blood cell $\vec{z}$ count of $11.4 \times 10^{9} / 1$ with $60 \%$ neutrophils, $30 \%$ lymphocytes, $8 \%$ monocytes, and $2 \%$ basophils. His blood glucose concentration was raised at $14.2 \mathrm{mmol} / \mathrm{l}$. The electrocardio- $\vec{\theta}$ gram indicated nothing remarkable and showed normal voltage. The patient's sputum contained Gram positive cocci and rods as well as Gram negative rods. A Ziehl-Neelseno stain was negative. The chest radiograph showed an anterior left upper lobe mass that obscured the left heart bordero (fig 1).

Computed tomography the next day showed a pericardial ${ }^{\Phi}$ effusion and a mass contiguous with the pericardium with extension through the anterior chest wall (fig 2). Repeat윽 examination of the patient disclosed a raised jugular venous pressure, a pulsus paradoxus of $30 \mathrm{~mm} \mathrm{Hg}$, and tachycardia (130 beats/min). Emergency echocardiography confirmed the pericardial effusion and indicated right ventricular and right

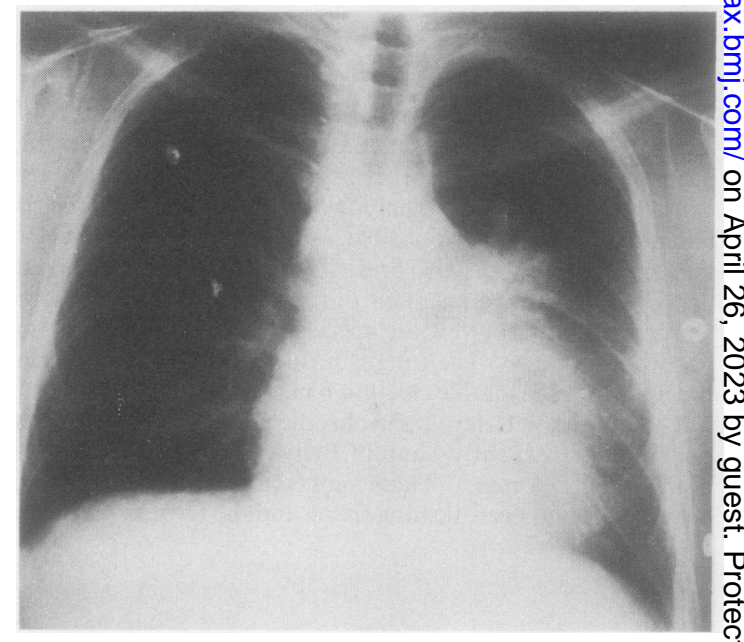

Fig 1 Posteroanterior chest radiograph showing a mass in the anterior segment of the left upper lobe. The cardiac silhouette is enlarged. 

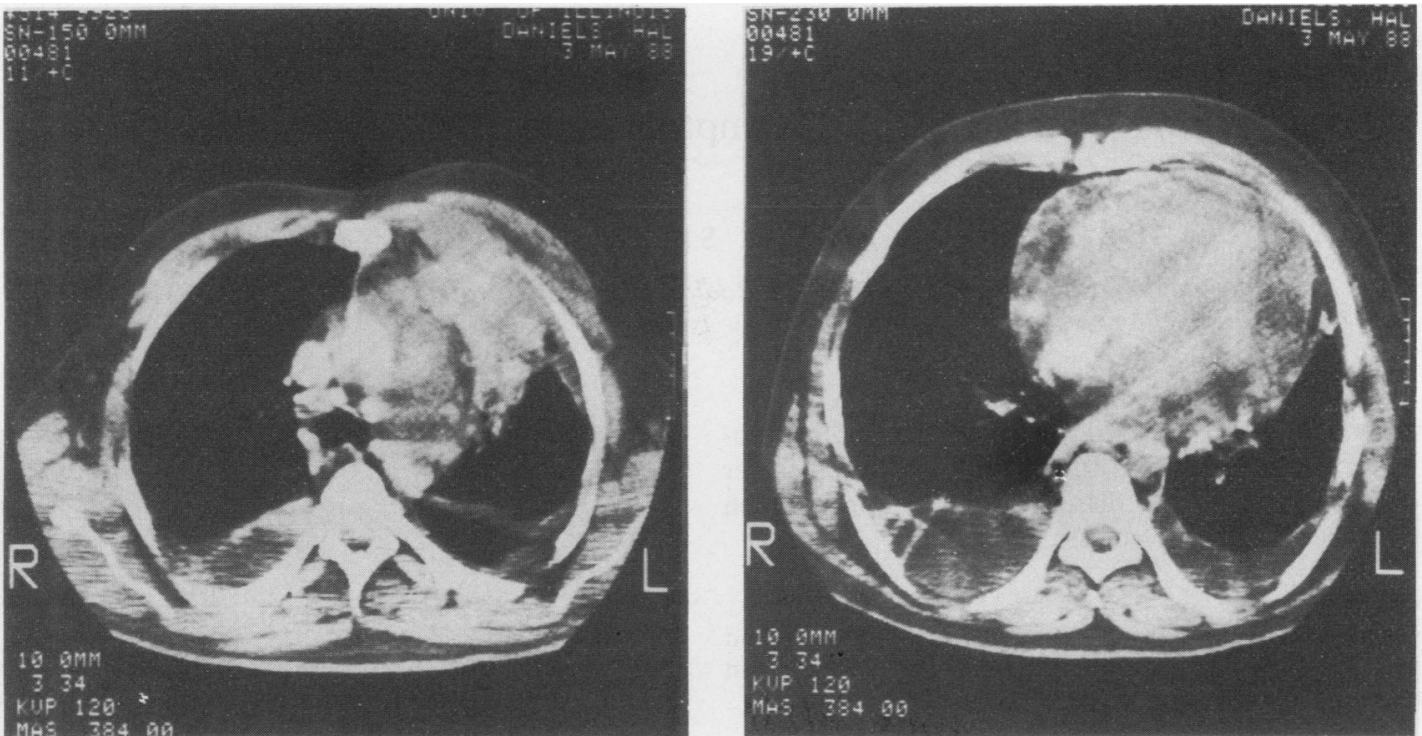

Fig 2 Views from the patient's computed tomogram showing bilateral pleural thickening, a mass contiguous with the pericardium extending into the soft tissue in the left chest (left panel), and a large pericardial effusion (right panel)

atrial diastolic collapse. Pericardiocentesis was performed and $800 \mathrm{ml}$ of grossly haemorrhagic fluid withdrawn. There was immediate correction of the tachycardia and the disturbance of diastolic cardiac function. Microscopic examination of the pericardial fluid showed squamous metaplasia but no microorganisms. The next morning transthoracic fine needle aspiration of the chest wall lesion was performed and the aspirate contained Gram positive filamentous rods, consistent with the appearance of actinomycetes. The patient was started on intravenous penicillin 20 million units/day and did well, with no further complaints of dyspnoea or orthopnoea.

\section{Discussion}

The radiographic and computed tomography findings of thoracic actinomycosis have been reviewed. ${ }^{46}$ Although actinomycosis of the pericardium is usually due to contiguous spread of thoracic actinomycosis it may follow primary myocardial or endocardial infection or haematogenous spread. ${ }^{7}$ Acute tamponade, constrictive pericarditis, and acute purulent pericarditis may be presenting manifestions of pericardial actinomycosis..$^{23-13}$ Five patients with pericardial tamponade have been reported in papers published in English, ${ }^{38-10}$ two of whom survived, both having required pericardiocentesis. One subsequently underwent surgical pericardiectomy and the other thoracotomy and pericardiectomy. ${ }^{34}$

We report the second case of acute pericardial tamponade due to a massive pericardial effusion caused by actinomycosis, in which the patient survived through aggressive medical management and pericardial drainage. To our knowledge, this is the first case in which thoracic actinomycosis with contiguous spread to the pericardium has been shown by computed tomography. Actinomycotic infection should be included in the differential diagnosis when computed tomography shows thickened pericardium with a pericardial effusion, particularly when the adjacent lung is abnormal.

\section{References}

1 Brown JR. Human actinomycosis, a study of 181 subjects. Hum Pathol 1973;4:319-30.

2 Kasper JA, Pinner M. Actinomycosis of the heart: report of a case with actinomycotic emboli. Arch Pathol 1930;10:687-96.

3 Orloff JJ, Fine MJ, Rihs JD. Acute cardiac tamponade due to cardiac actinomycosis. Chest 1988;93:661-3.

4 Flynn MW, Felson B. The roentgen manifestations of thoracic actinomycosis. AJR 1970;110:707-16.

5 Allen HA, Scatariage JC, Kim MA. Actinomycosis: CT findings in six patients. $A J R$ 1987;149:1255-8.

6 Webb WR, Sagel SS. Actinomycosis involving the chest wall: CT findings. $A J R$ 1982;139:1007-9.

7 Dattaa JS, Raff MJ. Actinomycotic pleuropericarditis. Am Rev Respir Dis 1974;110:338-41.

8 Pereira JW. Actinomycosis of the pericardium. Medical Annals of the District of Columbia 1962;29:28-33.

9 Mohan K, Dass SI, Kemble EE. Actinomycosis of pericardium. JAMA 1974:229:321.

10 Ramsdale DR, Gautam PL, Perera B, Charles RG. Cardiac tamponade due to actinomycosis. Thorax 1984;39:473-4.

11 Zoeckler S. Cardiac actinomycosis: a case report and review of the literature. Circulation 1941;3:854-8.

12 Corness A, Shookhoff HB. Actinomycosis of the heart simulating rheumatic fever: report of three cases of cardiac actinomycosis with a review of the literature. Arch Intern Med 1944;74:11-27.

13 Schlossberg D, Franco-Jove D, Woodward C, Shulman J. Pericarditis with effusion caused by Actinomyces israelli. Chest 1976;69:680-2 